\title{
Análise de polimorfismos do gene MC1R associados a fenótipos humanos de pigmentação na população brasileira
}

\section{MC1R gene polymorphisms analysis associated with human pigmentation phenotypes on the brazilian population}

\author{
Marano LAํㅜ, Simões $\mathrm{AL}^{1}$, Donadi EA ${ }^{2}$, Mendes-Junior $\mathrm{CT}^{3}$
}

Marano LA, Simões AL, Donadi EA, Mendes-Junior CT. Análise de polimorfismos do gene MC1R associados a fenótipos humanos de pigmentação na população brasileira. Saúde, Ética \& Justiça. 2013;18(Ed. Especial):55-61.

\begin{abstract}
RESUMO: Dentre os genes conhecidos por influenciarem a variação normal de pigmentação de olhos, pele e cabelos em humanos, o gene MC1R (receptor de melanocortina 1) é o mais bem caracterizado até o momento. A atuação do MC1R ocorre pela produção de uma proteína transmembrana nos melanócitos, responsável pela regulação da produção de melanina nos mesmos. Sabe-se que a atuação do MC1R determina a proporção entre eumelanina (coloração castanha/preta) e feomelanina (amarela/vermelha) presente nos melanócitos. O presente trabalho tem como objetivo analisar os SNPs conhecidos do gene MC1R com o propósito de se avaliar a influência da diversidade deste gene em características como a presença de sardas e variação da pigmentação dos olhos, pele e cabelos em humanos. Foram analisados 29 SNPs conhecidos da região codificadora do gene MC1R em 296 indivíduos da região de Ribeirão Preto, SP. A extração do DNA foi feita pela técnica de salting-out. A região codificadora do gene $\mathrm{MC1R}(951 \mathrm{pb})$ foi amplificada em uma única reação de PCR, a qual foi sequenciada em um analisador genético ABI-PRISM 310 por eletroforese capilar, utilizando-se os mesmos primers empregados para a amplificação. Dos 29 SNPs avaliados, 22 deles mostraram variação nas amostras estudadas, sendo que metade deles demonstrou estar associados a características de pigmentação. Observou-se um conjunto de SNPs associados claramente à fenótipos relacionados à feomelanina $(+1645 \mathrm{~A}$, +1831 T,+1858 T e +2260 C), enquanto outros se relacionam à ocorrência de eumelanina (+1558 G, $+2322 \mathrm{G}$, +2346 A). O presente trabalho apresenta associações significativas entre SNPs individuais e pigmentação de olhos, cabelos e pele, sendo que nosso dados confirmam que tal gene também desempenha papel relevante na variação de pigmentação na população Brasileira.
\end{abstract}

PALAVRAS-CHAVE: MC1R; Polimorfismos; Pigmentação; Pele; Olhos; Cabelo; População brasileira.

\footnotetext{
* Este trabalho consiste em parte da Dissertação de Mestrado do aluno Leonardo Arduino Marano, intitulada "Análise de polimorfismos do gene MC1R associados a fenótipos humanos de pigmentação na população brasileira". Versão completa será submetida ao periódico Forensic Science International: Genetics ou a outro equivalente.

${ }^{1}$ Departamento de Genética, Faculdade de Medicina de Ribeirão Preto, Universidade de São Paulo, Ribeirão Preto, SP, Brasil.

2 Divisão de Imunologia Clínica, Departamento de Clínica Médica, Faculdade de Medicina de Ribeirão Preto, Universidade de São Paulo, Ribeirão Preto, SP, Brasil.

${ }^{3}$ Departamento de Química, Faculdade de Filosofia, Ciências e Letras de Ribeirão Preto, Universidade de São Paulo, Ribeirão Preto, SP, Brasil.

Endereço para correspondência: C. T. Mendes-Junior. Departamento de Química. Faculdade de Filosofia, Ciências e Letras de Ribeirão Preto da Universidade de São Paulo. Avenida dos Bandeirantes, 3900. Ribeirão Preto, SP, Brasil. CEP: 14040-901.

E-mail: ctmendes@ffclrp.usp.br
} 


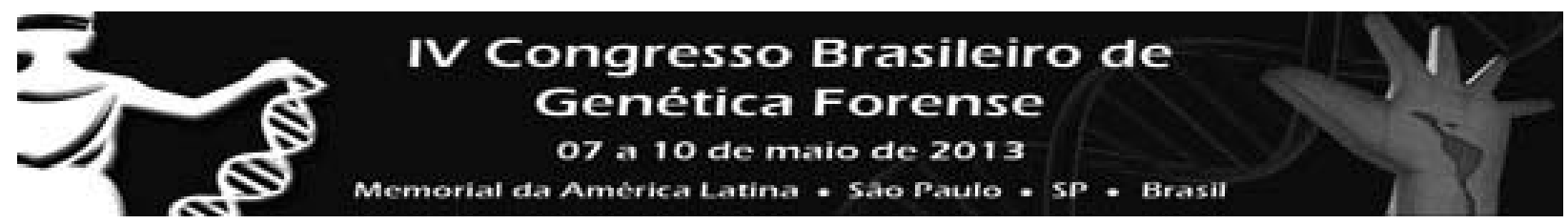

\section{INTRODUÇÃO}

A vanços recentes na genética humana parecem ter identificado marcadores potencialmente úteis associados à caracteres externamente visíveis. Em casos nos quais os bancos de perfis genéticos não são completos o suficiente, a predição desses caracteres poderia ser de grande ajuda nas investigações e rastreamento de suspeitos no futuro ${ }^{1,2}$. A associação entre marcadores genéticos e características morfológicas tem sido intensamente estudada na tentativa de se obter informações sobre feições físicas a partir de material genético extraído de amostras biológicas como manchas de sangue, pelos e outros fragmentos. Alguns estudos já revelaram polimorfismos associados à cor da pele, olhos e cabelo ${ }^{3-6}$; espessura do fio de cabelo, formato da face e estatura ${ }^{7-10}$.

As variações na cor da pele, olhos e cabelo são principalmente devidas ao conteúdo e distribuição da melanina nas células especializadas chamadas melanócitos. Muitos genes estão envolvidos no processo de melanogênese (TYR, ASIP, HERC2, SLC24A5, SLC45A2, MC1R, UGT1A, BNC2, etc), agindo em vários processo celulares, como controle de $\mathrm{pH}$, transporte transmembrana, vias de sinalização e indução/ repressão da transcrição ${ }^{11,12}$.

Entre todos os genes conhecidos que influenciam a variação da pigmentação, o gene do receptor 1 da melanocortina (MC1R - MIM 155555) é o mais bem caracterizado até agora ${ }^{13}$ Esse gene codifica uma proteína transmembrana de sete passos nos melanócitos, responsável pela produção de melanina, regulando a proporção de feomelanina (cor marrom/preta) e eumelanina (amarela/vermelha). O MC1R, que pertence a família dos receptores associados à proteína $G$ (GPCRs), é ativado pelo hormônio melanócitoestimulante ( $-\mathrm{MSH})$. Quando ativado, ele aciona a proteína $\mathrm{G}$, que faz com que a adenilato ciclase sintetize cAMP, aumentando seus níveis. Os níveis aumentados de cAMP alteram a transcrição de uma vasta gama de genes, incluindo o da tirosinase (TYR), levando à síntese de eumelanina. No entanto, uma redução parcial ou ausência dessa sinalização desencadeia a produção de feomelanina ${ }^{14}$.

Diversos alelos do MC1R já foram associados aos cabelos ruivos, pele clara e sardas em europeus ${ }^{15,16}$. Esses fenótipos estão relacionados principalmente à queda na atividade do $\mathrm{MC1R}$ devido à fatores como redução da expressão na superfície do melanócito, do acoplamento da proteína $\mathrm{G}$ e da capacidade de ligação ao hormônio ${ }^{17-19}$. Vários estudos também já mostraram associações de variantes do MC1R com susceptibilidade ao melanoma ${ }^{20,21}$.

A confirmação desses resultados obtidos nos trabalhos realizados em outras populações geneticamente mais homogêneas, como a europeia pode ser de extrema importância. Considerandose a grande variabilidade fenotípica e genética da população brasileira, com padrões alélicos distintos, nota-se a importância da realização de estudos genéticos em uma população tão miscigenada. A partir das confirmações desses estudos, uma melhor compreensão das associações já encontradas poderia ser obtida.

\section{OBJETIVOS}

Avaliar a diversidade genética revelada pelo sequenciamento completo da região codificadora do gene MC1R em uma amostra da população brasileira, estratificada de acordo com a pigmentação da pele, cabelos e olhos e presença de sardas, identificando um conjunto de polimorfismos do gene MC1R que contribuam para a determinação desses caracteres externamente visíveis na população brasileira.

\section{MATERIAL E MÉTODOS}

Foram coletadas amostras de sangue de um total de 296 voluntários não aparentados dos sexos masculino e feminino dos diferentes grupos étnicos que compõe a população brasileira, com idade variando de 18 a 40 anos, recrutados, em sua grande maioria, no Hemocentro de Ribeirão Preto (HCFMRP-USP), tendo todos assinado um termo de consentimento (Processo CEP-FFCLRP 433/2008). Estes indivíduos foram classificados através de um questionário em grupos de acordo com a cor dos olhos (azul, verde, mel, castanho claro e castanho escuro), cabelos (ruivos, loiros, castanhos e pretos) e pele (de I a VI) segundo o sistema proposto por Fitzpatrick ${ }^{22}$, utilizado em outros estudos que abordam a pigmentação humana ${ }^{23}$. Além disso, foi avaliada a presença ou ausência de sardas.

O DNA das amostras de sangue foi então extraído através de salting-out (24) e a região codificadora do MC1R (951 pb) foi amplificada em um 


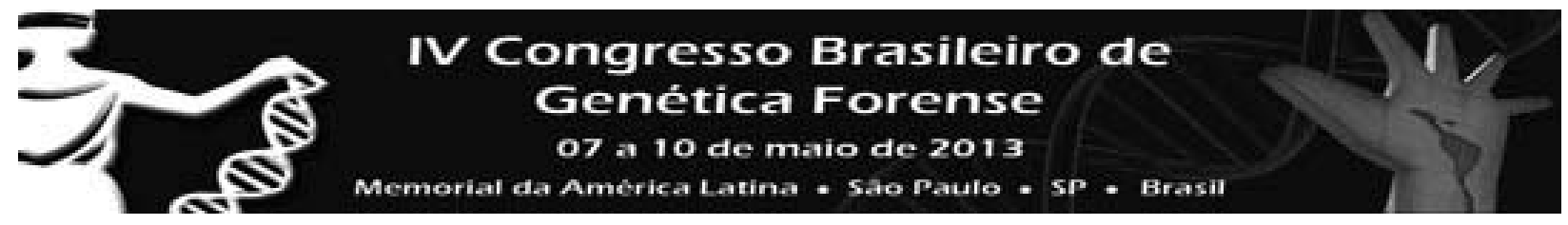

único fragmento de $\mathrm{PCR}$, posteriormente sequenciado em um analisador genético ABI PRISM-310. A região codificante completa do $M C 1 R$ foi amplificada utilizando-se os primers já descritos por Branicki ${ }^{25}$. Os produtos amplificados (1124pb) foram visualizados por eletroforese em gel de agarose de $0,8 \%$ corado por brometo de etídio. As reações de sequenciamento foram feitas usando o kit $A B I$ PRISM BigDye Terminator Cycle Sequencing Ready Reaction Kit@ (Amersham Pharmacia Biotech, EUA) usando os mesmos primers utilizados na etapa de PCR. Os produtos das reações foram sequenciados diretamente num analisador genético ABI-310 (Applied Biosystems, Foster City, CA, USA).

A leitura e alinhamento das sequências foram feitos pelo programa Lasergene SeqMan $7.0 \circledR$ (DNASTAR, Inc., EUA) com ênfase em 29 loci polimórficos previamente descritos. Esses loci foram selecionados por serem reconhecidamente polimórficos e por terem sido empregados em diversos estudos sobre a genética da pigmentação humana envolvendo o gene MC1R, sendo muitos deles já associados a características fenotípicas em populações europeias ${ }^{26-28}$.

Foram realizados cálculos de frequências alélicas e heterozigose, equilíbrio de HardyWeinberg e associações dos fenótipos aos genótipos aos níveis alélico e genotípico através do Teste exato de Fisher e cálculo dos valores de Odds Ratio (OR) com intervalo de confiança de 95\% empregando-se o programa GraphPad Instat $3.06^{29}$.

\section{DISCUSSÃO}

\section{Frequencias alélicas e heterozigose}

Do total de 29 loci selecionados, observouse que 7 deles não apresentaram qualquer variação nas amostras analisadas, possuindo apenas um alelo. Vinte e um dos 22 SNPs restantes se mostraram bialélicos, enquanto que um único SNP $(+1690)$, previamente descrito como bialélico, apresentou em nossas análises um terceiro alelo desconhecido até então (alelo T). Essa mutação encontrada gera a alteração do aminoácido Glicina para o aminoácido Cisteína na posição 310 da cadeia protéica. Em contrapartida, um locus previamente descrito como trialélico $(+1831)$ apresentou apenas dois alelos em nossas amostras.
Considerando o critério de definição de $1 \%$ para loci polimórficos, observamos que 13 deles não podem ser considerados polimórficos na população brasileira. Do total dos 9 loci polimórficos, 3 desses poderiam ser considerados como alelos de variação comum (freqüência maior que $5 \%$ no alelo menos frequente). No entanto, quando comparamos nosso dados à outras frequências globais ${ }^{30}$ percebemos que não é inesperado o fato de que vários destes loci tenham se apresentado monomórficos $(+1513$, +1580, +1627, +1632, +1664, +1698, +1739, $+1805,+1844,+1884,+1966)$, uma vez que todos esses marcadores possuem uma frequência extremamente baixa em todas as outras amostras populacionais analisadas (Africanas, Asiáticas, Europeias e Norte-americanas).

Desconsiderando-se os marcadores que não apresentaram variação, o menor valor de heterozigose observado $\left(H_{0}\right)$ foi de zero no locus +1846, enquanto o maior valor foi de 0,2376 no locus +2322. Já a heterozigose esperada $\left(H_{S}\right)$ variou de 0,0035 nos loci $+1580,+1627,+1645$ e +1664 até 0,2416 no SNP +2322.

\section{Equilibrio de Hardy-Weinberg}

As análises do equilíbrio de Hardy-Weinberg mostraram que quatro das 22 análises realizadas com a amostra total apresentaram desvios $($ loci $+1558,+1846,+1868$ e +1966$)$, todos devido ao déficit de heterozigotos nas amostras analisadas. Em nossas amostras, muito provavelmente, um dos fatores de desvio atuantes seja a presença de mistura étnica. Sabe-se da alta miscigenação da população de Ribeirão Preto, já tendo sido caracterizada para marcadores de ancestralidade, com proporções europeia, africana e ameríndia de $59 \%$, 34\% e $7 \%$ em média, respectivamente ${ }^{31,32}$. Este fator, associado à ocorrência de casamentos preferenciais no que se refere à ancestralidade e pigmentação da pele, pode resultar em estratificação populacional, caracterizando deficiência de heterozigotos na amostra total (efeito Wallund).

Foram avaliadas as associações entre fenótipos e genótipos, representadas pelos respectivos valores obtidos de significância $(p)$ pelo teste exato de Fisher e seus valores de Odds Ratio (OR). A Tabela 1 possui as categorias fenotípicas utilizadas nas análises, separadas por locus a fim de se avaliar a presença da associação. 


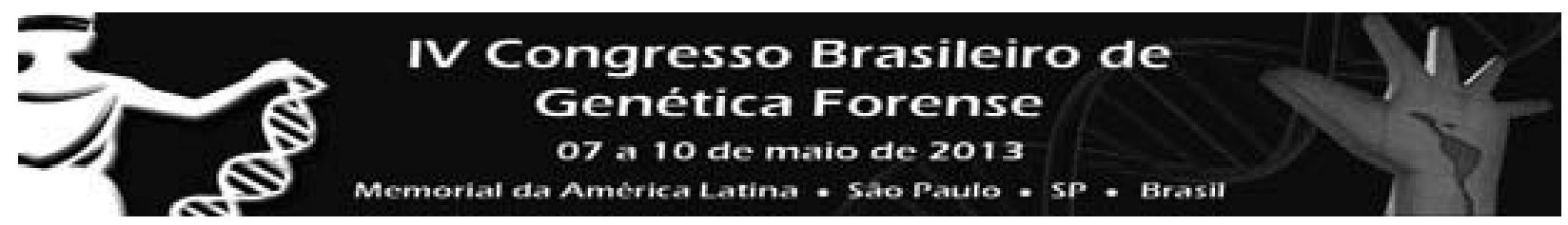

TABELA 1. Valores de Odds Ratio para as associações alélicas entre SNPs do MC1R e características fenotípicas. Cores representam o valor de $p: 0,05 \leq p \leq 0,10$ (cinza claro); $p \leq 0,05$ (cinza); $p \leq 0,01$ (preto)

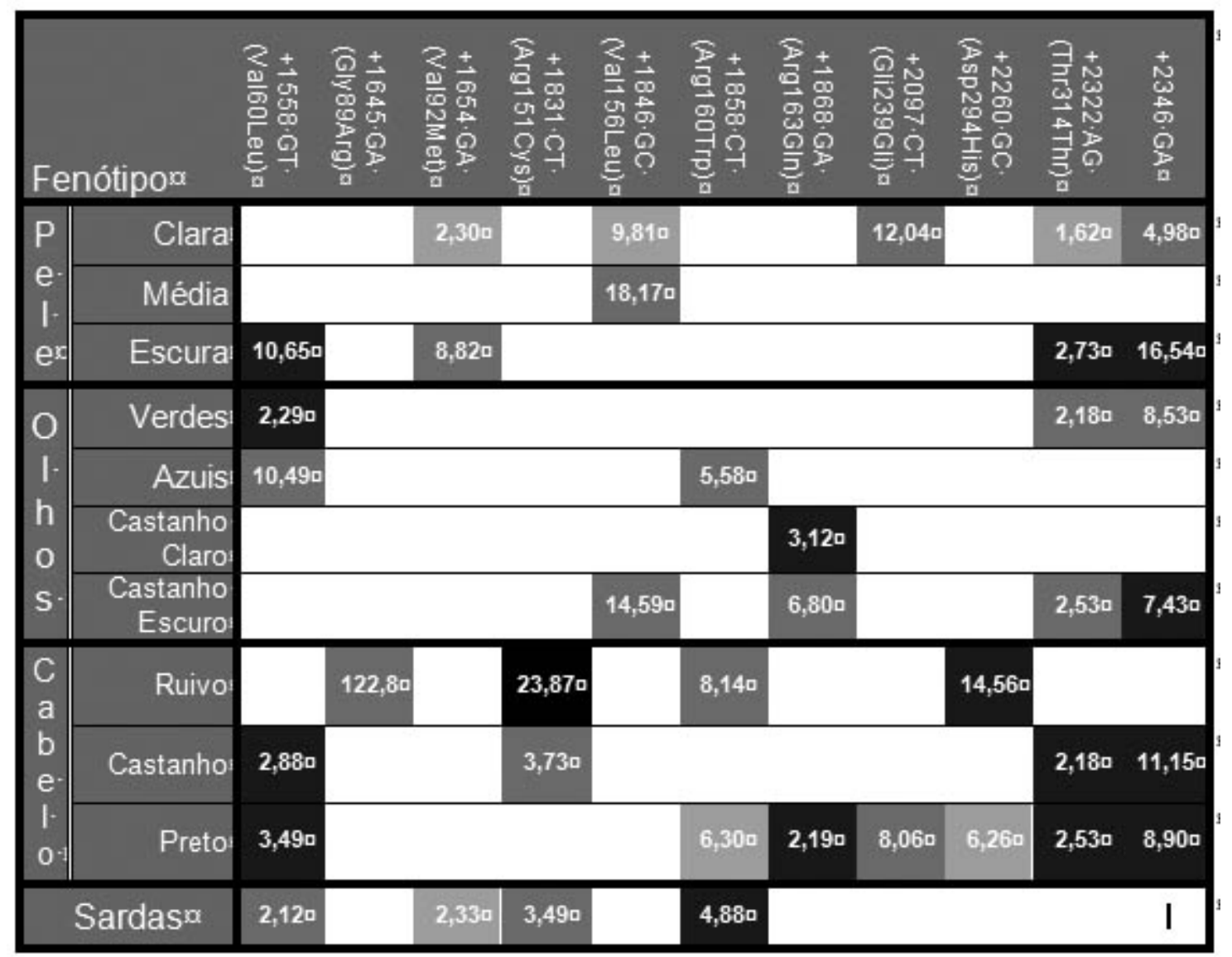

\section{Associações encontradas}

O segundo loop intracelular do $M C 1 R$ foi apontado como sendo uma região altamente conservada entre os vertebrados, bem como entre os subtipos humanos de receptores de melanocortina $(M C 2 R, M C 3 R, M C 4 R \text { e } M C 5 R)^{18}$. Esse domínio dos GPCRs foi demonstrado como sendo um dos mais importantes no funcionamento desses receptores, por ser justamente o sítio de acoplamento e ativação das proteínas $\mathrm{G}$ e, consequentemente, na produção de CAMP $^{33}$. Podemos observar que a maior parte das associações de SNPs $(+1831,+1846,+1858,+1868)$ encontradas no presente estudo relacionam-se com aqueles aminoácidos situados justamente nesse segundo loop intracelular (Figura 1). Não seria de se esperar que houvesse tantas mutações num trecho tão conservado evolutivamente e tão essencial na função do receptor. No entanto, o fato de, ao longo da evolução, o homem ter perdido os pelos que o protegiam da radiação solar pode ser a explicação para tais mutações nesse trecho. A partir do momento que as migrações para fora da África começaram, para regiões de menor incidência solar, pode-se considerar que houve um relaxamento da pressão seletiva sobre o MC1R, permitindo o surgimento e manutenção de mutações que gerassem novos receptores com função reduzida, inviáveis até então numa região tão sujeita a radiação UV como a África. Esses receptores menos eficientes, por outro lado, possivelmente foram selecionados positivamente em regiões de baixa latitude por gerarem fenótipos mais claros, úteis na fixação da vitamina $D$, pela absorção através da pele da pouca quantidade de luz disponível 28,34 .

Estudos também mostraram que algumas variantes do $M C 1 R$ podem apresentar padrões anômalos do transporte intracelular através do retículo endoplasmático (RE), resultando numa localização celular alterada do receptor ${ }^{18,19,35,36}$. Enquanto o esperado seria que 0 receptor selvagem fosse encontrado na superfície celular dos melanócitos, estes estudos mostram que algumas variantes do MC1R(Val60Leu, Arg151Cys 


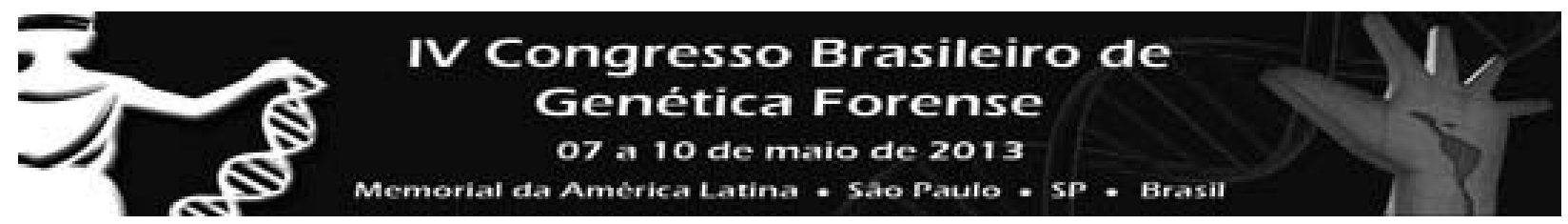

e Arg160Trp) podem ter seu número de receptores reduzido na superfície, devido à retenção no interior da célula parcial ou totalmente, geralmente no RE; enquanto outras mutações (Asp294His) podem até ter uma densidade de superfície maior que o selvagem ${ }^{36}$.

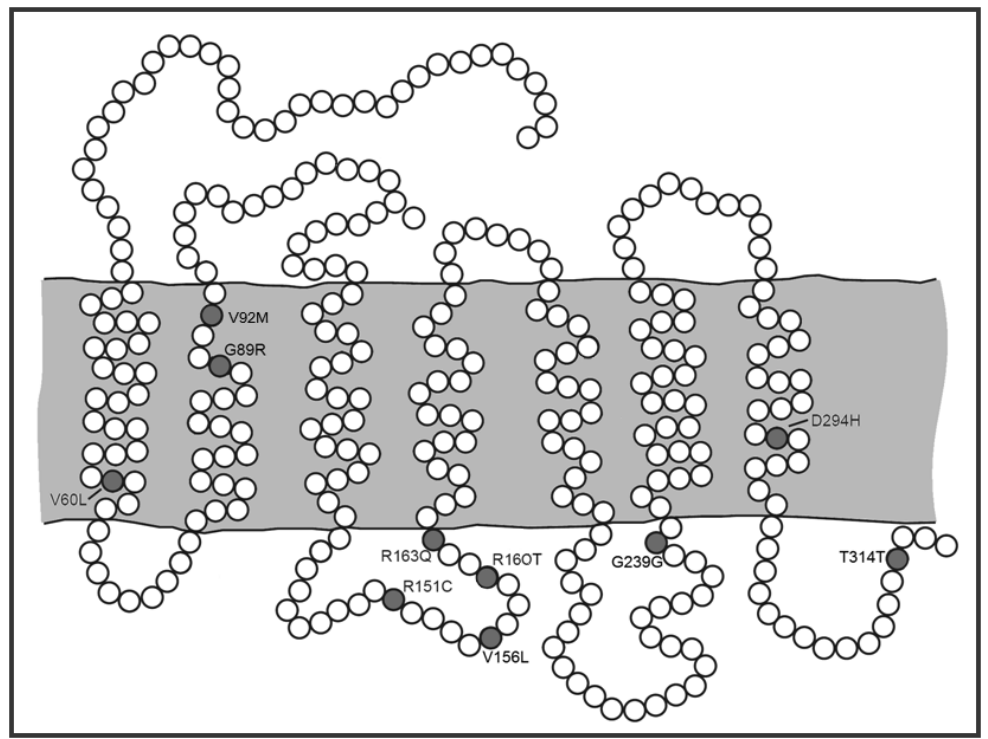

Figura 1. Representação do MC1R mostrando as substituições de aminoácidos associadas aos fenótipos (em preto) e os loops intracelulares (IL)

A associação vista no SNP +1558 de olhos azuis e pele negra em um mesmo alelo pode ser aparentemente contraditória, no entanto, sabe-se que o $M C 1 R$ não é o único gene que controla as vias da melanogênese. Além disso, sabe-se que algumas mutações do MC1R podem afetar de maneiras diversas a proporção feo/eumelanina nos diferentes tecidos, com a ocorrência de indivíduos de pele escura e cabelos claros e vice-versa ${ }^{37}$.

\section{CONCLUSÕES}

Este foi o primeiro estudo de associação de fenótipos de pigmentação em uma população tão miscigenada quanto a brasileira envolvendo o MC1R. O presente estudo mostra a relevância da região codificadora do MC1R e consistência com diversos estudos funcionais. Observa-se um conjunto de SNPs associados claramente à fenótipos relacionados à feomelanina, enquanto outros se relacionam à ocorrência de eumelanina. Nosso estudo permitiu a constatação dessas associações a níveis alélico e genotípico tanto com SNPs sinônimos quanto não-sinônimos.

Atualmente não se tem muito conhecimento a respeito da possível influência das regiões promotora e 3'UTR na atuação do MC1R. Seria de grande interesse a genotipagem dessas regiões a fim de se avaliar sua influência na pigmentação em humanos em estudos futuros. Variações poderiam elucidar a atuação sobre o MC1R, principalmente em relação a possíveis aumentos ou reduções nos níveis de expressão gênica, que poderiam se refletir em variações fenotípicas da pele, olhos e cabelos.

AGRADECIMENTOS: Este trabalho teve auxílio financeiro do Conselho Nacional de Desenvolvimento Científico e Tecnológico (CNPq, processo 478843/2009-7). Agradecemos Sandra Silva Rodrigues dos Santos, Flávia Tremeschin de Almeida, Maria do Carmo Tomitão Canas e Ana Lúcia Pimentel por sua ajuda inestimável. Também agradecemos a todos doadores de amostras por sua cooperação. L.A.M. foi financiado por uma bolsa de Mestrado (130167/2009-6) e C.T.M.J. por uma bolsa de pesquisador (305493/2011-6) do CNPq. 


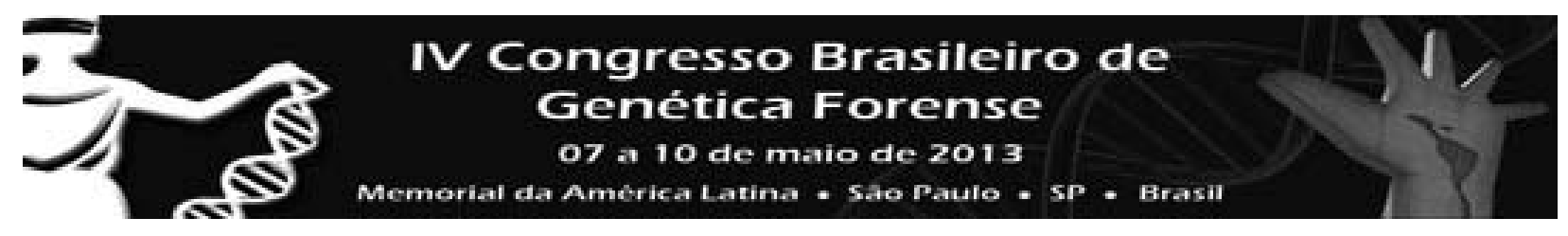

Marano, LA; Simões, AL; Donadi, EA; Mendes-Junior CT. MC1R gene polymorphisms analysis associated with human pigmentation phenotypes on the brazilian population. Saúde, Ética \& Justiça. 2013;18(Ed. Especial):55-61.

\begin{abstract}
Among the known genes influencing eye, skin and hair normal pigmentation variation, the MC1R (melanocortin 1-receptor) gene is the best characterized so far. The activity of MC1R occurs due the production of a transmembrane protein in melanocytes, responsible for regulating the production of melanin. It is known that the performance of MC1R determines the ratio of eumelanin (brown /black color) and pheomelanin (yellow/ red) present in melanocytes. This study aims to analyze known SNPs of the MC1R gene in order to evaluate the influence of this gene diversity on features like freckles and pigmentation variation of eyes, skin and hair in humans. We analyzed 29 known SNPs in the coding region of MC1R gene in 296 individuals from the region of Ribeirão Preto, Brazil. DNA extraction was performed using the salting-out technique. The MC1R gene coding region $(951 \mathrm{pb})$ was amplified in a single PCR reaction, which was sequenced on a ABI PRISM-310 genetic analyzer by capillary electrophoresis, using the same primers used for amplification. Of the 29 SNPs evaluated, only 22 showed variation in the samples studied, half of them showing to be associated with pigmentation characteristics. We observed a set of SNPs clearly associated to pheomelanin $(+1645 \mathrm{~A},+1831 \mathrm{~T},+1858 \mathrm{~T}$ e $+2260 \mathrm{C}$ ), while others related to eumelanin occurrence $(+1558 \mathrm{G},+2322 \mathrm{G},+2346 \mathrm{~A})$. Our study shows significant associations between individual SNPs and eyes, hair and skin pigmentation. The results presented here confirm that this gene also plays a relevant role in the pigmentation variation in the Brazilian population.
\end{abstract}

KEYWORDS: MC1R; Polymorphisms; Pigmentation; Skin; Eyes; Hair; Brazilian population.

\title{
REFERÊNCIAS
}

1. Kayser M, Schneider PM. DNA-based prediction of human externally visible characteristics in forensics: motivations, scientific challenges, and ethical considerations. Forensic Sci Int Genet. 2009;3(3):15461.

2. Kayser $M$, de Knijff $P$. Improving human forensics through advances in genetics, genomics and molecular biology. Nat Rev Genet. 2011;12(3):17992.

3. Frudakis $\mathrm{T}$, Terravainen $\mathrm{T}$, Thomas M. Multilocus OCA2 genotypes specify human iris colors. Hum Genet. 2007;122(3-4):311-26.

4. Branicki W, Brudnik U, Wojas-Pelc A. Interactions between HERC2, OCA2 and MC1R may influence human pigmentation phenotype. Ann Hum Genet. 2009;73(2):160-70.

5. Weeden T, Stefano J, Duan S, Edling A, Hou L, Chuang $W L$, et al. A retro-inverso alpha-melanocyte stimulating hormone analog with MC1R-binding selectivity. J Pept Sci. 2011;17(1):47-55.

6. Ruiz Y, Phillips C, Gomez-Tato A, Alvarez-Dios J, Casares de Cal M, Cruz R, et al. Further development of forensic eye color predictive tests. Forensic Sci Int Genet. 2013;7(1):28-40.

7. Watson A. New tools. A new breed of high-tech detectives. Science. 2000;289(5481):850-4.

8. Perola M, Ohman M, Hiekkalinna T, Leppavuori J, Pajukanta P, Wessman M, et al. Quantitative-traitlocus analysis of body-mass index and of stature, by combined analysis of genome scans of five Finnish study groups. Am J Hum Genet. 2001;69(1):117-23.

9. Pulker $\mathrm{H}$, Lareu MV, Phillips C, Carracedo A. Finding genes that underlie physical traits of forensic interest using genetic tools. Forensic Sci Int-Gen. 2007;1(2):100-4.

10. Fujimoto A, Kimura R, Ohashi J, Omi K, Yuliwulandari $R$, Batubara $L$, et al. A scan for genetic determinants of human hair morphology: EDAR is associated with Asian hair thickness. Hum Mol Genet. 2008;17(6):83543.

11. Wilson S, Ginger RS, Dadd T, Gunn D, Lim FL, Sawicka $M$, et al. NCKX5, a natural regulator of human skin colour variation, regulates the expression of key pigment genes MC1R and alpha-MSH and alters cholesterol homeostasis in normal human melanocytes. Adv Exp Med Biol. 2013;961:95-107.

12. Jacobs LC, Wollstein A, Lao O, Hofman A, Klaver CC, Uitterlinden AG, et al. Comprehensive candidate gene study highlights UGT1A and BNC2 as new genes determining continuous skin color variation in Europeans. Hum Genet. 2013;132(2):147-58.

13. Gerstenblith MR, Goldstein AM, Fargnoli MC, Peris $\mathrm{K}$, Landi MT. Comprehensive evaluation of allele frequency differences of $\mathrm{MC1R}$ variants across populations. Hum Mutat. 2007;28(5):495-505.

14. Makova K, Norton $\mathrm{H}$. Worldwide polymorphism at the MC1R locus and normal pigmentation variation in humans. Peptides. 2005;26(10):1901-8.

15. Sturm RA. A golden age of human pigmentation 


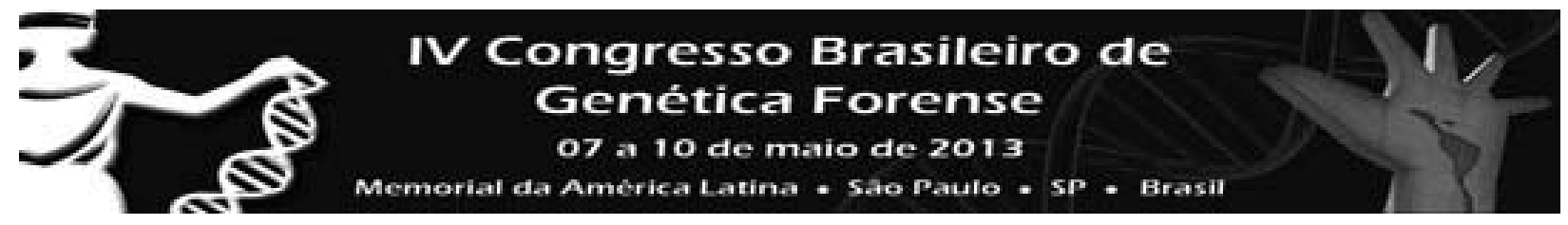

genetics. Trends Genet. 2006;22(9):464-8.

16. Harding RM, Healy E, Ray AJ, Ellis NS, Flanagan N, Todd C, et al. Evidence for variable selective pressures at MC1R. Am J Hum Genet. 2000;66(4):1351-61.

17. Beaumont KA, Newton RA, Smit DJ, Leonard JH, Stow JL, Sturm RA. Altered cell surface expression of human MC1R variant receptor alleles associated with red hair and skin cancer risk. Hum Mol Genet. 2005;14(15):2145-54.

18. Sanchez-Laorden BL, Herraiz C, Valencia JC, Hearing VJ, Jimenez-Cervantes C, Garcia-Borron JC. Aberrant trafficking of human melanocortin 1 receptor variants associated with red hair and skin cancer: Steady-state retention of mutant forms in the proximal golgi. J Cell Physiol. 2009;220(3):640-54.

19. Perez Oliva AB, Fernendez LP, Detorre C, Herraiz C, Martinez-Escribano JA, Benitez J, et al. Identification and functional analysis of novel variants of the human melanocortin 1 receptor found in melanoma patients. Hum Mutat. 2009;30(5):811-22.

20. Pellegrini C, Fargnoli MC, Suppa M, Peris K. MC1R variants predisposing to concomitant primary cutaneous melanoma in a monozygotic twin pair. BMC Med Genet. 2012;13:81.

21. Ghiorzo P, Bonelli L, Pastorino L, Bruno W, Barile M, Andreotti $\mathrm{V}$, et al. MC1R variation and melanoma risk in relation to host/clinical and environmental factors in CDKN2A positive and negative melanoma patients. Exp Dermatol. 2012;21(9):718-20.

22. Fitzpatrick TB. The validity and practicality of sunreactive skin types I through VI. Arch Dermatol. 1988;124(6):869-71.

23. Rana BK, Hewett-Emmett D, Jin L, Chang BH, Sambuughin N, Lin M, et al. High polymorphism at the human melanocortin 1 receptor locus. Genetics. 1999;151(4):1547-57.

24. Miller SA, Dykes DD, Polesky HF. A simple salting out procedure for extracting DNA from human nucleated cells. Nucleic Acids Res. 1988;16(3):1215. PubMed PMID: 3344216.

25. Branicki W, Brudnik U, Kupiec T, Wolanska-Nowak P, Wojas-Pelc A. Determination of phenotype associated SNPs in the MC1R gene. J Forensic Sci. 2007;52(2):349-54.
26. Mengel-From J, Wong TH, Morling N, Rees JL, Jackson IJ. Genetic determinants of hair and eye colours in the Scottish and Danish populations. BMC Genet. 2009;10:88

27. Wong TH, Rees JL. The relation between melanocortin 1 receptor $(\mathrm{MC} 1 \mathrm{R})$ variation and the generation of phenotypic diversity in the cutaneous response to ultraviolet radiation. Peptides. 2005;26(10):1965-71.

28. Rees JL. Genetics of hair and skin color. Annu Rev Genet. 2003;37:67-90.

29. GraphPad Software I, EUA. 3.06 ed. San Diego, California; 2003

30. Savage SA, Gerstenblith MR, Goldstein AM, Mirabello L, Fargnoli MC, Peris K, et al. Nucleotide diversity and population differentiation of the melanocortin 1 receptor gene, MC1R. BMC Genet. 2008;9:31.

31. Ferreira LB, Mendes-Junior CT, Wiezel CE, Luizon MR, Simoes AL. Genomic ancestry of a sample population from the state of Sao Paulo, Brazil. Am J Hum Biol. 2006;18(5):702-5.

32. Muniz YC, Ferreira LB, Mendes-Junior CT, Wiezel CE, Simoes AL. Genomic ancestry in urban AfroBrazilians. Ann Hum Biol. 2008;35(1):104-11.

33. Shan J, Weinstein H, Mehler EL. Probing the structural determinants for the function of intracellular loop 2 in structurally cognate G-protein-coupled receptors. Biochemistry. 2010;49(50):10691-701.

34. Soejima M, Koda Y. Population differences of two coding SNPs in pigmentation-related genes SLC24A5 and SLC45A2. Int J Legal Med. 2007;121(1):36-9.

35. Beaumont KA, Shekar SN, Newton RA, James MR, Stow JL, Duffy DL, et al. Receptor function, dominant negative activity and phenotype correlations for MC1R variant alleles. Hum Mol Genet. 2007;16(18):2249-60.

36. Sanchez-Laorden BL, Jimenez-Cervantes C, GarciaBorron JC. Regulation of human melanocortin 1 receptor signaling and trafficking by Thr-308 and Ser-316 and its alteration in variant alleles associated with red hair and skin cancer. J Biol Chem. 2007;282(5):3241-51.

37. Van Raamsdonk CD, Barsh GS, Wakamatsu K, Ito S. Independent regulation of hair and skin color by two $\mathrm{G}$ protein-coupled pathways. Pigment Cell Melanoma Res. 2009;22(6):819-26. 